\title{
Western European climate, and Pinot noir grape harvest dates in Burgundy, France, since the 17th century
}

\author{
Yves M. Tourre ${ }^{1,2, *}$, Daniel Rousseau ${ }^{3}$, Lionel Jarlan ${ }^{4}$, Emmanuel Le Roy Ladurie $^{5}$, \\ Valérie Daux ${ }^{6}$ \\ ${ }^{1}$ Météo-France, 31057 Toulouse, France \\ ${ }^{2}$ Lamont-Doherty Earth Observatory (LDEO) of Columbia University, 10964-1707 Palisades, New York, USA \\ ${ }^{3}$ Conseil Supérieur de la Météorologie, 31057 Toulouse, France \\ ${ }^{4}$ Institut de Recherches pour le Développement/Centre d'Etudes Spatiales de la BIOsphère (IRD/CESBIO), 31401 Toulouse, France \\ ${ }^{5}$ Collège de France, 75005 Paris, France \\ ${ }^{6}$ Laboratoire des Sciences du Climat et de l'Environnement (LSCE), 91191 Gif-sur-Yvette, France
}

\begin{abstract}
Time-series of growing season air temperature anomalies in the Parisian region and of Pinot noir grape harvest dates (GHD) in Burgundy (1676-2004) are analyzed in the frequency domain. Variability of both time-series display 3 significant frequency-bands (peaks significant at the $5 \%$ level): (1) a low-frequency-band (multi-decadal) with a 25 yr peak period, (2) a 3 to 8 yr band period (inter-annual) with a $3.1 \mathrm{yr}$ peak period, and (3) a 2 to $3 \mathrm{yr}$ band period (quasi-biennial) with a $2.4 \mathrm{yr}$ peak period. Joint sea surface temperature/sea level pressure (SST/SLP) EOF analyses based on data from the 20th century along with spatio-temporal patterns for the above frequency-bands, are presented. SST anomalies were found to display early significant spatial SST patterns in the north Atlantic ocean (air temperature lagging by 6 mo) similar to those obtained from EOF analyses. It is proposed that the robust power spectra for the above frequencybands are linked with Atlantic climate variability modulating western European climate: (1) the global Multi-Decadal Oscillation (MDO) with its Atlantic Multi-decadal Oscillation (AMO) footprint, (2) the Atlantic Inter-Annual (IA) fluctuations, and (3) the Atlantic Quasi-Biennial (QB) fluctuations. Moreover these specific western European climate signals are perceived as contributors to the timing of GHD in Burgundy. Thus, advance knowledge on the evolution and phasing of the above climate fluctuations become important elements for viticulture and wine industry management, since anthropogenic effects could have modified time-series patterns, particularly since the mid-1980s.
\end{abstract}

KEY WORDS: Western European climate variability - Climate change - Grape harvest dates · Pinot noir · Burgundy · GHD

Resale or republication not permitted without written consent of the publisher

\section{INTRODUCTION}

During the 20th century, natural climate fluctuations have been identified within well-defined frequency bands in the Atlantic basin. The global Multi-Decadal Oscillation (MDO; Schlesinger \& Ramankutty 1994) displays sea surface temperature (SST) patterns in the Atlantic Ocean, which are similar to those of the Atlantic Multi-decadal Oscillation (AMO; Kerr 2000).
The AMO partially reflects the variability of the thermohaline circulation (THC; Delworth \& Mann 2000). Other known climate signals in the Atlantic basin are comprised of Quasi-Decadal (QD: 8 to $14 \mathrm{yr}$ ), InterAnnual (IA: 3 to 8 yr) and Quasi-Biennial (QB: 2 to 3 yr) period bands. Multi-decadal climate fluctuations are also present in paleo-climatic records and biological proxies (e.g. tree-ring and coral time-series; Gray et al. 2004, Hetzinger et al. 2008). 
Combined interactions among the above climate fluctuations may contribute to cooling/warming of SST in the North Atlantic, associated with cooler/warmer Western European summertime temperatures (Sutton $\&$ Hodson 2005). The variability of long-term temperature time-series which have been produced for the Parisian region (333 yr; Rousseau 2009), Central England (335 yr; Manley 1974), and De Bilt, Netherlands (from 1678; van Engelen \& Geurts 1985) can thus be considered representative of the western European climate variability at different time-scales.

The natural climate variability discussed above and its impact on ecosystems and plant phenology has been discussed elsewhere (Jones \& Goodrich 2008). Based upon the concept of historical climatology, proxy data have also been used to identify temperature variations over western Europe. For example, grape harvest dates (GHD: the number of days from August 31st) have been used as proxies to reconstruct temperature time-series back to the 14th century in Burgundy, France (Chuine et al. 2004) and in the Vienna region (Austria) for the 1523-2007 period (Maurer et al. 2009). It is recognized that the climate variability which occurred during different periods had an influence on viticulture practices by modifying the percentage of water content in grapes which, in turn, imposed different harvest deadlines (García de Cortázar 2006) directly affecting GHD.

Linkage between climate variability over western Europe and the yield of grapevines after the springsummer growing season (GS: April to September) deserves further investigation. GS corresponds to the period from bud break, flowering, 'véraison' (color change and start of sugar accumulation), and maturity. This paper establishes robust relationships between western European natural climate fluctuations and the Pinot noir variety (so-called 'Noble' grape) GHD in Burgundy. The long time-series of GS temperature anomalies in the Parisian region, and of Pinot noir GHD in Burgundy (Daux 2004) for the 1676-2004 period, are analyzed in the frequency domain in an attempt to isolate key climate signals possibly associated with GHD variability.

It is acknowledged, however, that other changes in vine growing and production practices due to socioeconomic pressures could have induced artificially low GHD variability (Chabin et al. 2007). The integrated mechanisms mentioned above lead to the official 'ban des vendanges' in France (i.e. the official date of grape harvest issued by the local authority; Encyclopédie 1777), with consequences on the wine industry and on the quality of wines, which belong to the French patrimony. Finally, on-going anthropogenic activities could modify - or could have modifiednatural climate fluctuations.

\section{DATA AND METHODOLOGY}

\subsection{Datasets and time-series}

2.1.1. Air temperature time-series: Information on dominant climate variability was obtained using long instrumental time-series of monthly mean air temperature anomalies in the Parisian region. The monthly mean temperature (1757-1886) published by Renou in 1887, expanded by Morin from 1676 until 1713, with data from the Paris/Montsouris observatory until 2008, define the time-series for the Parisian region (Rousseau 2009). The lack of reliable observations for the 1713-1756 period has been dealt with using correlated time-series from central England (Parker \& Horton 2005) and from De Bilt, Netherlands (correlations of 0.82 and 0.86 , respectively, using 1200 monthly anomalies during the 19th century). The Parisian region time-series has been homogenized (Moisselin et al. 2002). Monthly temperature anomalies are calculated from the 1801-1900 base period. Smoothed evolutions of the 3 temperature time-series (11 yr moving average) are assumed to represent western European climate variability.

2.1.2. Grape harvest date time-series: GHD timeseries from 16 vineyards in Burgundy were combined to form a unique long time-series (1370-2004; see Daux 2004). The Pinot noir variety was chosen, since data were continuously available and highly sensitive to climatic variations (Jones 2008). From the raw data and an 11 yr moving average anomaly time-series, a sub time-series starting in 1676 was used.

2.1.3. Sea surface temperature and sea level pressure datasets: Global, monthly SST, and sea level pressure (SLP) $5 \times 5^{\circ}$ gridded datasets, north of $50^{\circ} \mathrm{S}$ and for the 20th century (Basnett \& Parker 1997, Rayner et al. 2003) were detrended and normalized (monthly anomalies divided by respective standard deviations). The global SST dataset since 1857 and north of $20^{\circ} \mathrm{S}$ (courtesy of Alexei Kaplan, Columbia University) was used for correlation analyses with the Parisian region time-series.

\subsection{Methodology}

2.2.1. Spectral analyses: To identify significant frequencies from GS temperature anomalies in the Parisian region and GHD during the 1676-2004 period, multi-taper-method (MTM) spectra were obtained for both time-series. MTM allows for a better resolution in the frequency domain than fast Fourier transform. Three tapers (or filters) were used for reasonable frequency resolution (equal to half that of the Rayleigh frequency), providing sufficient degrees of 
freedom for signal/noise decomposition. Spectral frequency-bands (with peaks significant at the 5 and $1 \%$ levels relative to a spectrum obtained from a colored noise null-hypothesis) were obtained. Analyses (not shown) were also performed (1) before and after 1900 and (2) by season, to check the stability of the results and/or identify potential frequency changes as a function of time (from the so-called 'evolutive spectrum', Mann \& Park 1999).

Finally, results obtained from the MTM analyses and their potential linkages with global climate signals, joint and filtered SST/SLP datasets within the lead frequency bands were submitted to EOF analyses to identify significant spatio-temporal coherent patterns.

2.2.2. Correlation analysis between Parisian region and global SST time-series: After analyzing the evolution of GS air temperature anomalies in the Parisian region and of GHD since 1676 and finding key climate signals contributing to GHD variability, lead/lag correlations between global SST patterns and GS temperature anomalies were computed for the 1857-2004 period. SSTs were averaged over 3 mo moving windows. Only significant correlations ( $\mathrm{p}<1 \%$ from Student's $t$ test) were displayed. Lags are given in months starting in June at Year T. Thus a -6 mo lag corresponds to correlations between GS temperature at Year T, and SST anomalies during October-November-December of Year T-1. In the same year, a zero mo lag corresponds to a correlation between June-July-August SST anom- alies and GS temperatures. This approach allows isolating spatial oceanic SST patterns potentially linked with western European temperature.

\section{RESULTS}

\subsection{Growing season temperature anomalies and grape harvest date time-series}

The detailed GS temperature anomalies (from the 19th century mean) for the Parisian region, Central England, and De Bilt are displayed in Fig. 1. When 11 yr running means are applied to the 3 time-series, a synchronous temporal coherence is highlighted, indicating that they represent quite well the climate variability over western Europe. Some discrepancies are found during the 1785-1812 period for unknown reasons. Since the mid-1980s, GS temperatures have been rapidly increasing and display anomalies higher than those from previous warm periods (i.e. reaching $1.5^{\circ} \mathrm{C}$ ).

The GS temperature anomalies in the Parisian region and the 11 yr running means for both temperature and GHD time-series are displayed in Fig. 2. From 1676 until 1966, approximately 10 multi-decadal fluctuations (i.e. warm sequence followed by a cold sequence, separated by vertical black dashed lines in Fig. 2) can be identified. Since $\sim 1966$, the 11th fluctuation is much different, displays an overall sharp increase and will be

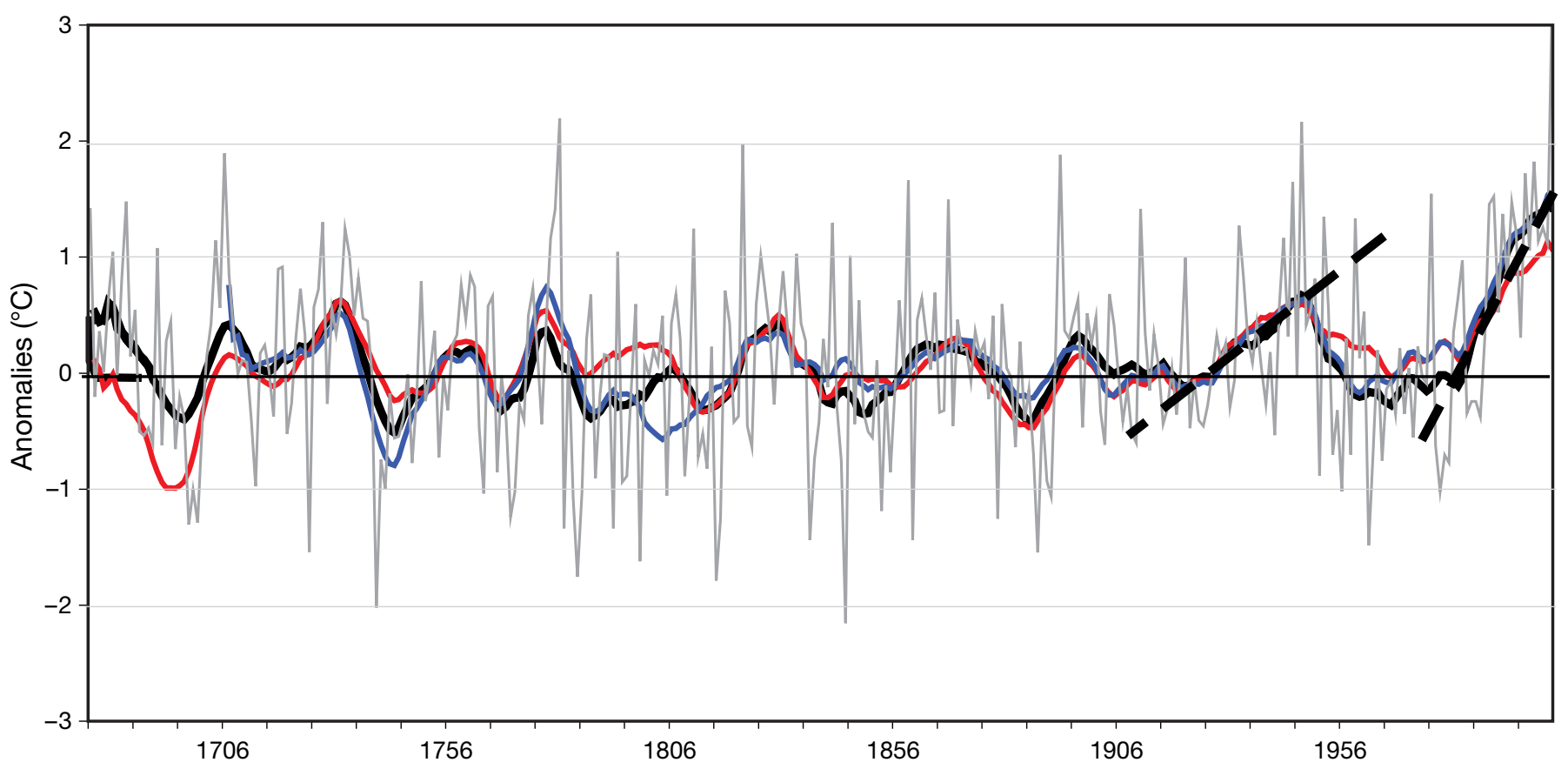

Fig. 1. Yearly growing season (GS) temperature anomalies (from the 19th century mean) for the 1676-2004 period in the Parisian region (thin grey line with yearly values). Thick black line: $11 \mathrm{yr}$ moving average temperature anomaly for the Parisian region, thick red line: Central England, and thick blue line: De Bilt, Netherlands. The bold slanted dashed lines during the 20th century highlight the sharpest temperature increase 
discussed later. The average difference between the warm and cold peaks for the first 10 fluctuations is $0.8^{\circ} \mathrm{C}$.

Pinot noir GHD in Burgundy is a good proxy for GS temperature, and a correlation $\mathrm{r}=-0.71$ was found by Etien et al. (2008). In Fig. 2 the smoothed GHD timeseries variability displays similarities to the temperature variability, leading to correlations of $r=-0.74$ and $r=$ -0.77 for raw data and for $11 \mathrm{yr}$ moving averaged values, respectively. GHD smoothed extrema are almost synchronous with smoothed temperature extrema during Fluctuations 1, 4, 8 and 10. Double GHD smoothed extrema are visible during Fluctuations 7 and 9. Phasing discrepancies in peak values did occur between GHD maximum and temperature maximum during Fluctuations 3 and 5. In some years GHD could be strongly influenced by wine growers to improve wine quality which might explain some differences with temperature extrema (i.e. Fluctuations 3, 5, end of Fluctuation 9). During Fluctuation 11, the 2 time-series evolved at the same rate with values increasing sharply after 1987. This abrupt change was noted by Cuccia (2008) who studied recent climate changes in Burgundy since 1961.

\subsection{Analyzing time-series in the frequency domain}

From the MTM spectral analyses, frequency-bands at least above the $90 \%$ confidence level from Monte Carlo simulation were present in both Parisian region temperature anomaly and GHD time-series. The MTM spectrum of GS temperature anomaly series in the Parisian region (1676-2004) is displayed in Fig. 3. Seven frequency-bands with significant peaks (5 and $1 \%$ levels) were identified: $2 \mathrm{QB}$ bands with $2.1 \mathrm{yr}$ and $2.4 \mathrm{yr}$ peak periods, 2 IA bands with 3.1 and $7.7 \mathrm{yr}$ peak periods, a QD band with a 14 yr peak period significant at the $5 \%$ level, and 2 multi-decadal (MD) bands with 25 and 55 yr peak periods. The 2.4 yr peak period is more significant during the 20th century, whilst the 2.1 period is more significant during 1676-1900 (not shown). The 25, 14, and $3.1 \mathrm{yr}$ peak periods are less significant when the MTM is performed with monthly values (as opposed to a single GS value per yr) and for the 20th century only. A significant 4 yr peak period ( $5 \%$ level) is present when MTM analysis is performed for winters only (discussed later). A $\sim 50-70$ yr band period (with a penta-decadal peak) dominates during summers. The $25 \mathrm{yr}$ peak period is more significant for both summers and winters during the 1676-1900 period.

The MTM spectrum of GHD (1676-2004) is displayed in Fig. 4. Only 4 frequency-bands above the $90 \%$ confidence level from Monte Carlo simulation, with significant peak periods (5 and $1 \%$ levels) are identified: a QB band with a 2.4 yr peak period significant at the $5 \%$ level, the IA band with 3.1 and $3.9 \mathrm{yr}$ peak periods significant at the 5 and $1 \%$ levels respectively, a MD band with a 25 yr peak period significant at the $5 \%$ level. While the $\sim 3.9$ and $25 \mathrm{yr}$ peak periods

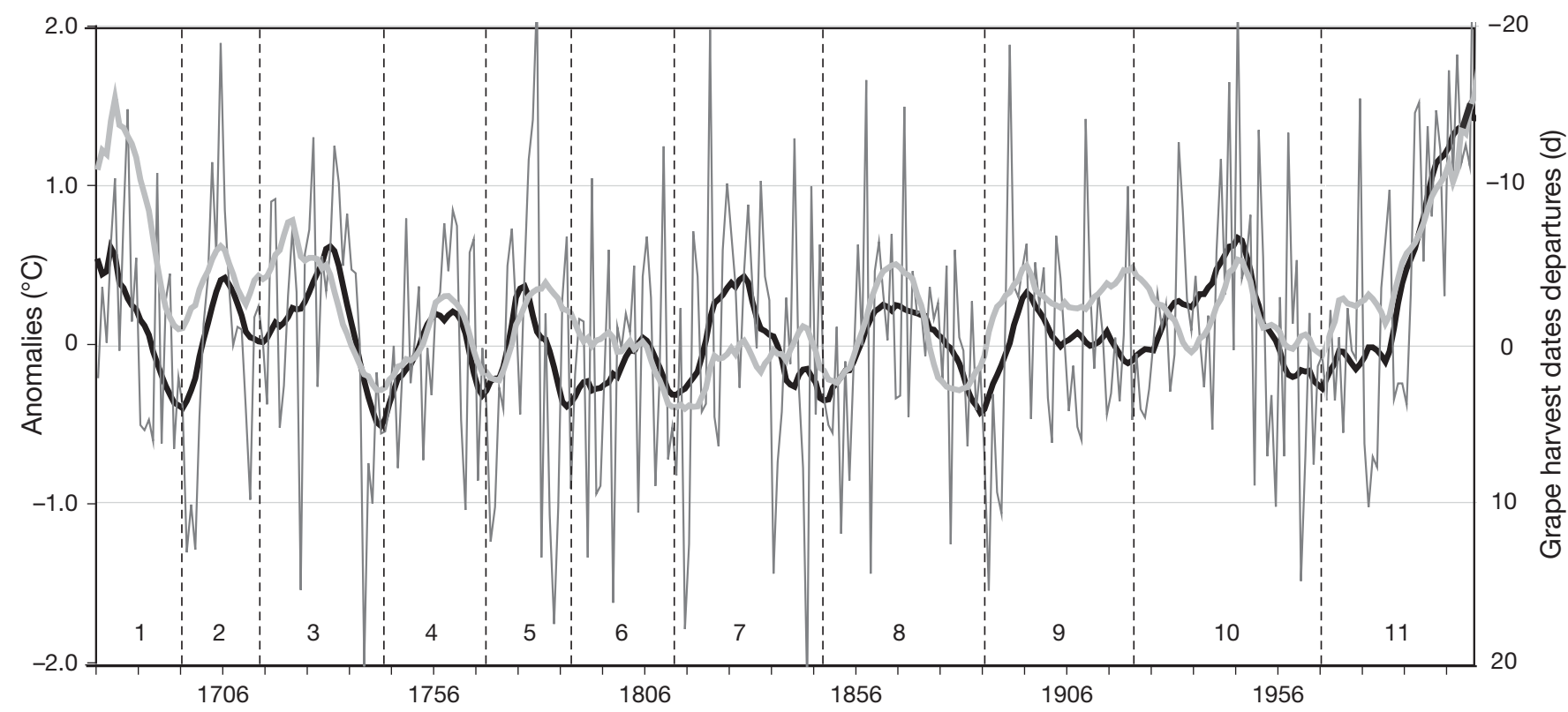

Fig. 2. Growing season (GS) temperature time-series in the Parisian region (thin grey line with yearly values) and the 11 yr moving average (thick black line) reproduced from Fig. 1. The $11 \mathrm{yr}$ moving average of grape harvest date (GHD) departures in days from August 31 (thick grey line) are superimposed for the same 1676-2004 period and are given on the right $y$-axis. A significant correlation of -0.77 was found between the 2 time-series. The 10 quasi-synchronous fluctuations in both time-series are separated by vertical black dashed lines 


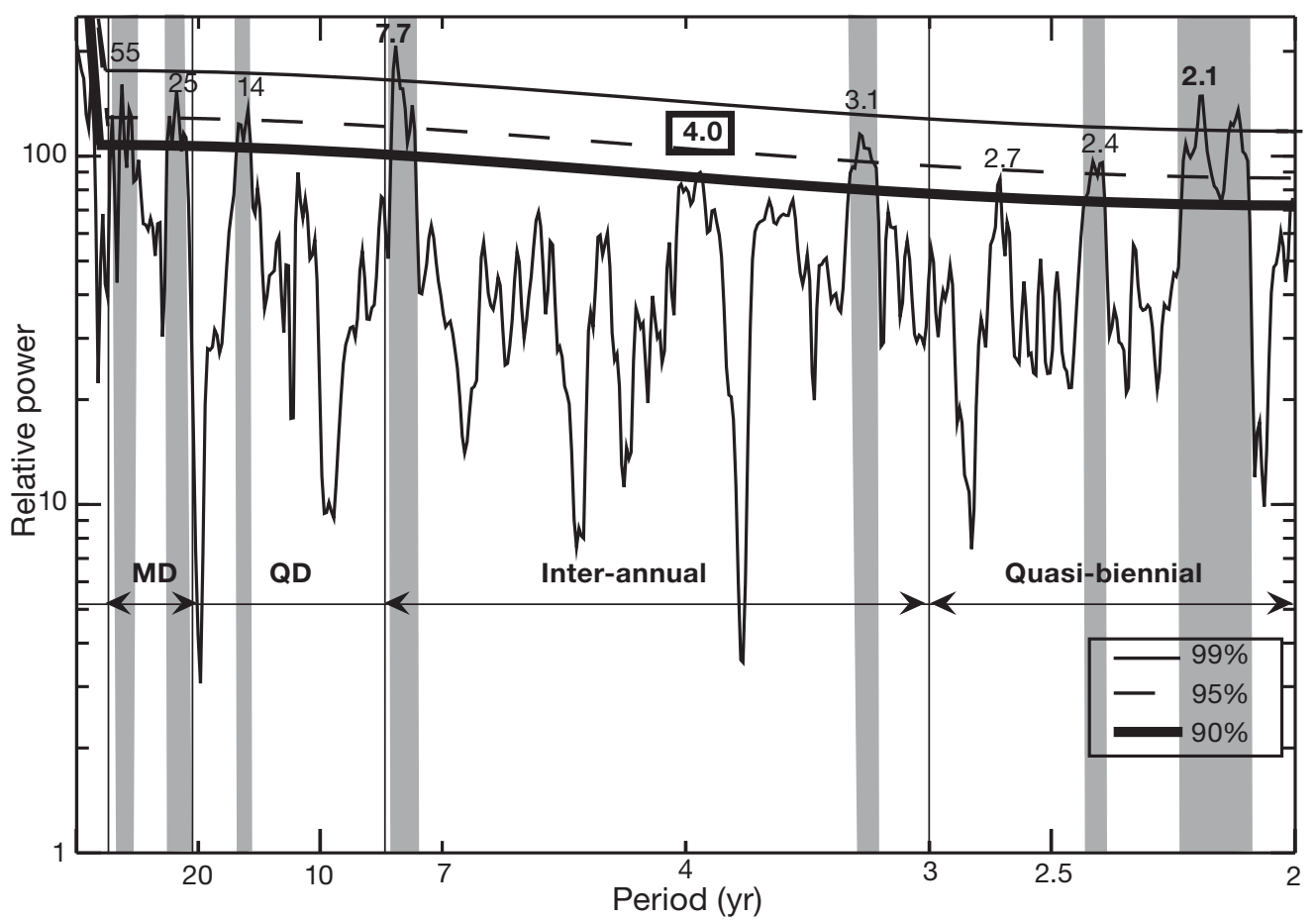

Fig. 3. Multi-taper-method spectrum of the growing season temperature anomalies for the Parisian region (1676-2004). Monte Carlo confidence levels: $90 \%=$ black thick line; $95 \%=$ black dashed line; $99 \%=$ black thin line. Frequency-bands above the $90 \%$ confidence levels are grey-shaded with significant peak-values at the 5 and $1 \%$ levels. The 4.0 yr period (small box) is barely significant during the growing season, but significant during the preceding winter. Periods for the Multi-Decadal (MD), Quasi-Decadal (QD), Inter-Annual (IA), and Quasi-Biennial (QB) signals are highlighted from left to right

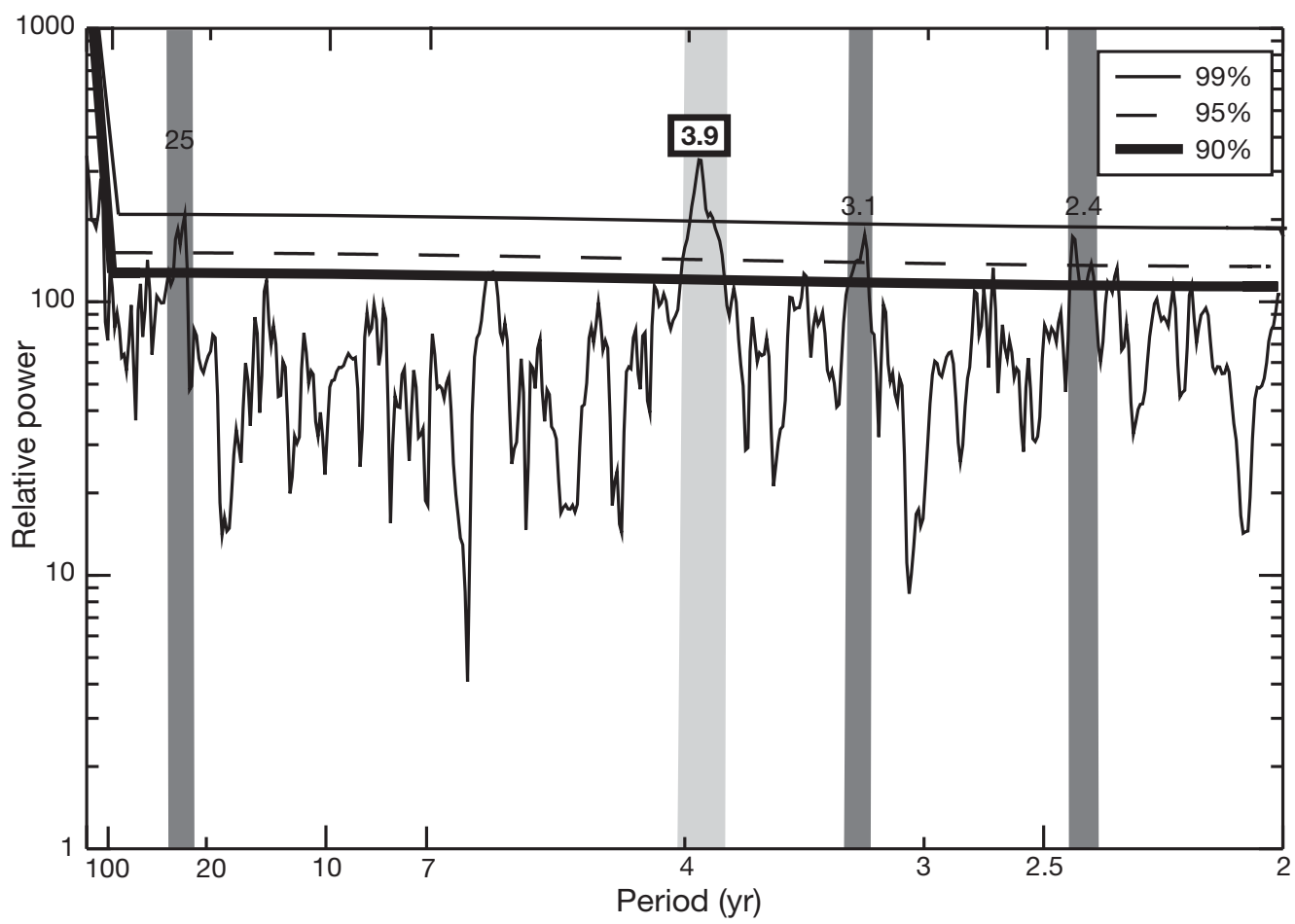

Fig. 4. Multi-taper-method spectrums as in Fig. 3, but for the grape harvest date (1676-2004 period). Light grey shading: frequency-band above the $99 \%$ confidence level; dark grey shading: frequency-bands above $95 \%$ confidence levels, also found in

Fig. 3. A highly significant $3.9 \mathrm{yr}$ period (small box) is close to the $4.0 \mathrm{yr}$ peak period of the preceding winter (cf. Fig. 3 ) 
dominate prior to 1900 , the 3.1 and $\sim 2.4$ yr peak periods dominate during the 20th century.

The 2 time-series have thus in common a $2.4 \mathrm{yr}(\mathrm{QB})$, $3.1 \mathrm{yr}$ (IA) and $25 \mathrm{yr}(\mathrm{MD})$ peaks during the entire period. The QB, IA and MD signals could correspond to known climate signals. A 3.9 yr peak period is significant at the $1 \%$ level in the GHD time-series spectrum.

\subsection{Joint SST/SLP mapping of MD, IA and QD climate signals}

The mapping of the MDO can be seen in Fig. 1 (Tourre et al. 2010). The global MDO changed phases twice during the 20th century, in the late 1920s and early 1970s. The SLP pattern displays alternate polarities in the tropical Atlantic, and must modulate the strength of the St. Helena subtropical anticyclone in the southern Atlantic. The Atlantic SST patterns resemble those of the AMO. The $40 \mathrm{yr}$ low-pass data used in the study might also include the effects of the Wolf-Gleissberg 70-100 yr solar cycle present in the total solar irradiance time-series (Yousef et al. 2000). The North Atlantic Ocean was cooler from the beginning of the century to late 1920s and from the beginning of the 1970s to the mid-1990s. The ups and downs in temperature and the phasing of the AMO could also be influenced by total solar irradiance and aerosols (volcanic and dust) changes (Ottera et al. 2010). These low-frequency patterns have had impacts on the climate of western Europe and modulated GHD.

The joint SST/SLP mapping of the IA, and QB climate signals during the 20th century, are obtained here from filtered EOF analyses. The Atlantic IA climate patterns ( $29 \%$ variance of the band-passed signal) are shown in Fig. 5. The maximum amplitude for the 3-4 yr band-passed IA occurred during the late 1960s to early 1970s, while minima occurred in the late 1910s, early 1920s, mid-1950s, and mid-1990s, 35 to 40 yr apart. The minimum values of SLP pattern are

Atlantic inter-annual climate signal (3-4 yr band-passed) : SST and SLP anomalies (29\%)
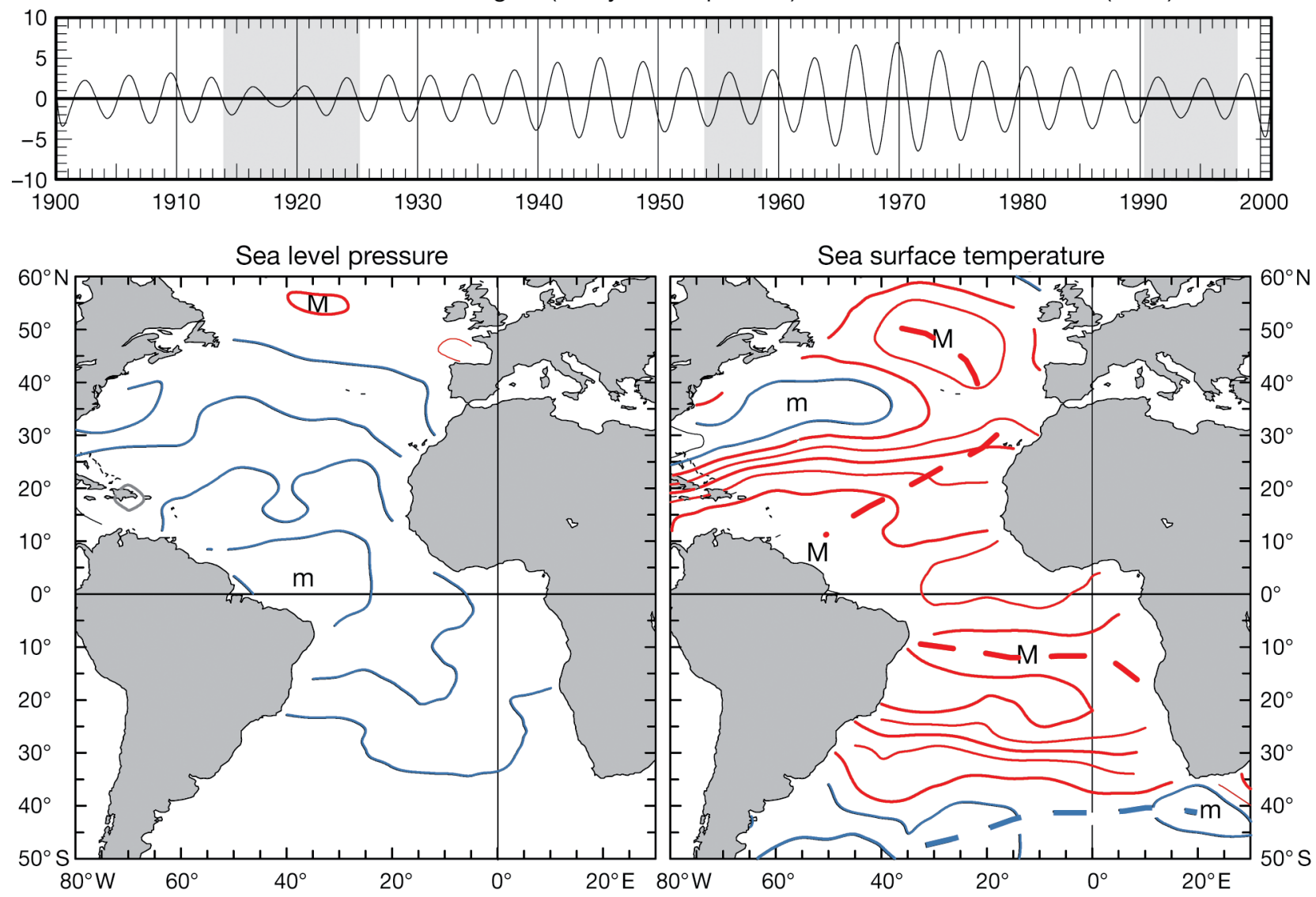

Fig. 5. The Atlantic Inter-Annual (IA) signal obtained from a 3-4 yr band-passed sea-surface temperature (SST) and sea-level pressure (SLP) EOF analysis. The standardized amplitude function (top) and the spatial loadings (bottom) left/right for SLP/SST are displayed. Isolines have increments of $0.1 \mathrm{hPa}$ (for SLP) and of $0.1^{\circ} \mathrm{C}$ (for SST). Red/blue isolines are for positive/negative values of the signal when the amplitude function is positive. $\mathrm{M} / \mathrm{m}$ are maximum/minimum values from -0.4 to $0.1 \mathrm{hPa}$ (SLP, bottom left) and from 0.5 to $-0.2^{\circ} \mathrm{C}$ (SST, bottom right). The thick red dashed line is to emphasize the horseshoe/tripole pattern in the north Atlantic. Periods with minimum values (approximately $40 \mathrm{yr}$ apart) of the amplitude function are shaded (top) 
found over the maximum values SST pattern in the tropical Atlantic, a signature of hydrostatic adjustment there. A horseshoe/tripole SST pattern is noticeable in the northern Atlantic, indicative of atmospheric anticyclone and anticyclonic gyre effects. This specific SST spatial pattern is likely linked to IA warming/cooling along the west European coastline, with immediate effects on the climate there.

The Atlantic QB climate patterns (25\% variance of the band-passed signal) are shown in Fig. 6. The amplitude function displays nodes which are again $\sim 40$ yr apart, while maximum amplitudes during the late 1930 s, early 1940 s, and the late 1960 s to early 1970s. The QB minima have a tendency to occur 5 to $10 \mathrm{yr}$ before the IA minima for unknown reasons. The SLP and SST patterns resemble that of the IA, implying similar physics at 2 different timescales (i.e. air-sea interactions and wind-driven fluxes). The horseshoe/tripole SST pattern is better defined in the northern Atlantic with the QB signal. Both IA and QB climate signals should have similar impacts on west European climate, possibly re-enforcing each other during the late 1930s to early 1940s and late 1960s to early $1970 \mathrm{~s}$, when both amplitude functions attained maximum values.

\subsection{Correlation between SSTs and growing season temperature anomalies in the Parisian region}

Lead/lag correlations between GS temperature anomalies in the Parisian region and global normalized SST anomalies for the 1857-2004 period were computed. Only significant patterns in the Atlantic and Indian oceans are displayed in Fig. 7. From lags -11 to -9 mo (i.e. during fall-winter preceding the GS temperatures) correlated anomalous SST spatial patterns are found first in the eastern Indian ocean. Then from lags -8 to $-2 \mathrm{mo}$, correlated SST spatial patterns are developing in the southern and northern Atlantic. During that period, correlations amplify in the northern Atlantic attain maximum values at lag 0 (with correlations >0.5). At that time the correlated SST pattern resemble the SST horseshoe/tripole patterns displayed in Figs. $5 \& 6$. The evolving Atlantic SST patterns from lag -5 to lag -1 are similar to those associated with SST patterns identified from both the IA and QB climate variability. When similar lead/lag correlations are computed for the GHD time-series, persistent SST spatial patterns occur in the northern Atlantic from lags -11 to $-6 \mathrm{mo}$, with polarity reversed to that of GS temperatures (the 2 time-series are indeed negatively correlated). From lags -3 to 0 mo, correlated SST spatial patterns are also found in the eastern Indian ocean where the QB climate signal associated with the monsoon circulation, dominates. Possible linkages between monsoon circulation, polar vortex oscillation over Eurasia, and winter/spring strength of the Azores anticyclone (possibly linked to the western European climate) have been suggested (Tourre et al. 2006). Both SST spatial patterns present in the northern Atlantic and Indian oceans are thus associated with IA and QB signals and contribute to climate variability over western Europe and the timing of GHD.

\section{DISCUSSION}

Wine grape harvest dates result from human decisions based upon the climate during the GS, and include socio-economic and technical factors (Le Roy Ladurie et al. 2006). 'Grape growing and wine production' however 'are largely weather and climate-driven enterprises' (Jones 2006), and represent a strong measure of the historic climates of wine growing regions. This study shows the potential role of Atlantic climate variability at different spatio-temporal scales on GHD. When the GS temperature anomalies in the Parisian region and the GHD in Burgundy time-series are compared during the 1676-2004 period (Fig. 2), 10 joint fluctuations are found for the 2 filtered time-series (lasting from 10 to $40 \mathrm{yr}, 5$ fluctuations being quasisynchronous). The last $20 \mathrm{yr}$ of the period (Fluctuation 11) show a rapid temperature increase (combined with negative departures of GHD) reaching anomalies higher than any of those attained during previous fluctuations, even during Fluctuations 1 and 2. The latter 2 fluctuations correspond to the last phase of the Maunder Minimum and the retreat of the Grindelwald Alpine glacier (Zumbühl 1980). The warming during Fluctuation 11 could be due to a combination of the strengthening of the polar vortex after the mid-1980s (with mainly positive phases of the Arctic Oscillation and of the North Atlantic Oscillation) and anthropogenic forcing, all having impacts on Pinot noir GHD (Chabin et al. 2007). Similar effects were observed for Cabernet sauvignon grapes and harvest dates in the Gironde region since 1988 (Bois 2007).

When the normalized time-series from MTM spectrum analyses were examined, 3 period-bands -2.4 , 3.1 , and 25 yr periods - have 3 significant peak periods (5\% level), and belong to both spectra in Figs $3 \& 4$. They could correspond to global MDO, a 3 to 4 yr IA climate signal, and a 2 to 3 yr QB climate signal.

The 25 yr peak period is present in the GHD spectrum. The 25 yr peak period is more significant prior to the 20th century and could correspond to the global MDO climate signal with specific SST patterns in the Atlantic Ocean (AMO), within a 20 to $60 \mathrm{yr}$ band period. These oscillations are associated with coherent 
Atlantic quasi-biennial climate signal (2-3 yr band-passed) : SST and SLP anomalies (29\%)

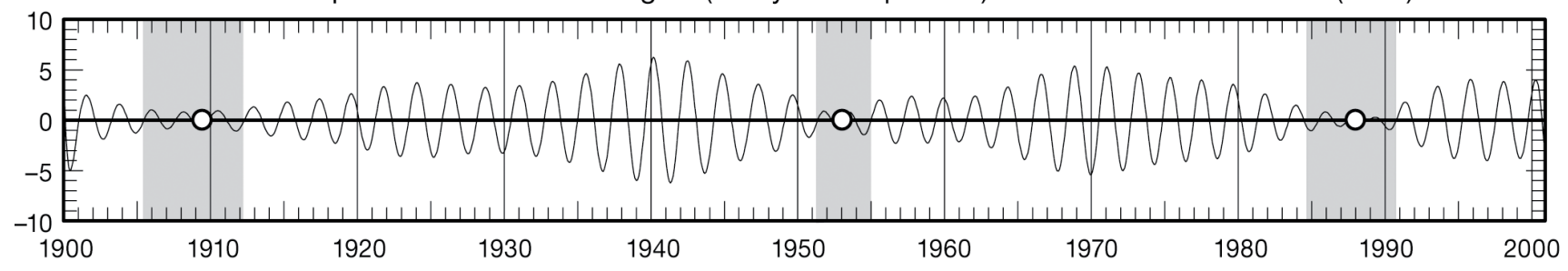

Sea level pressure



Fig. 6. Atlantic Quasi-Biennial (QB) signal from a 2-3 yr band-passed sea-surface temperature (SST) and sea-level pressure (SLP) EOF analysis. $\mathrm{M} / \mathrm{m}$ are maximum/minimum values from -0.5 to $0.1 \mathrm{hPa}$ (SLP, bottom left) and from 0.6 to $-0.2^{\circ} \mathrm{C}$ (SST, bottom right). Red/blue isolines are for positive/negative values of the signal when the amplitude function is positive. The thick red dashed line emphasizes the tripole pattern in the north Atlantic. Periods with nodes (white dots along the zero-axis of the amplitude function, top) are $\sim 40$ yr apart. They occur 2 to 4 yr before periods of minima (or weak values) of the Atlantic Inter-Annual (IA) IA climate signal

evolution of the Atlantic THC and meridional overturning circulation. This low-frequency variability modulates western European climate and likely has effects on GHD. Note that the associated AMO climate signal changed phases 3 times during the 20th century-late 1920s, early 1970s, and mid-1990s. During these periods, winters in France were on average warmer from the 1900s until the late 1920s when it became cooler until the late 1960s to early 1970s, and then became warmer again until at least the mid 1990s.

The significant peak periods for the QB and IA signals are present in both time-series. The Atlantic climate signals are shown to be associated with SST horseshoe/tripole structures in the northern Atlantic (indicative of the strength of the atmospheric anticyclone and of the anticyclonic gyre during springsummer: i.e. a stronger/weaker anticyclonic gyre with cooler/warmer temperatures at its center $\left(45^{\circ} \mathrm{W}, 35^{\circ} \mathrm{N}\right)$ and warmer/cooler temperatures on its edges, including the eastern Atlantic (Kushnir 1994). Moreover, a warmer/colder tropical Atlantic is associated with lower/higher tropical Atlantic SLP, through hydrostatic equilibrium, and would be associated with enhanced/ reduced Hadley circulation during spring-summer, conducive of blocking/weakening anticyclonic conditions over western Europe (Tourre et al. 2006). This should modulate solar and rainfall input and thus, harvest timing. QB and IA signals could also be modulated by the THC. These types of large scales conditions with impacts on viticulture have also been mentioned for the Bordeaux area (Jones \& Davis 2000).

The $7.7 \mathrm{yr}$ peak period identified in the GS temperature time-series is not significant in the GHD for unknown reasons. Similarities and differences between results obtained here and from Etien et a. (2008) could be due to their use of a smoothing Bartlett window (i.e. 

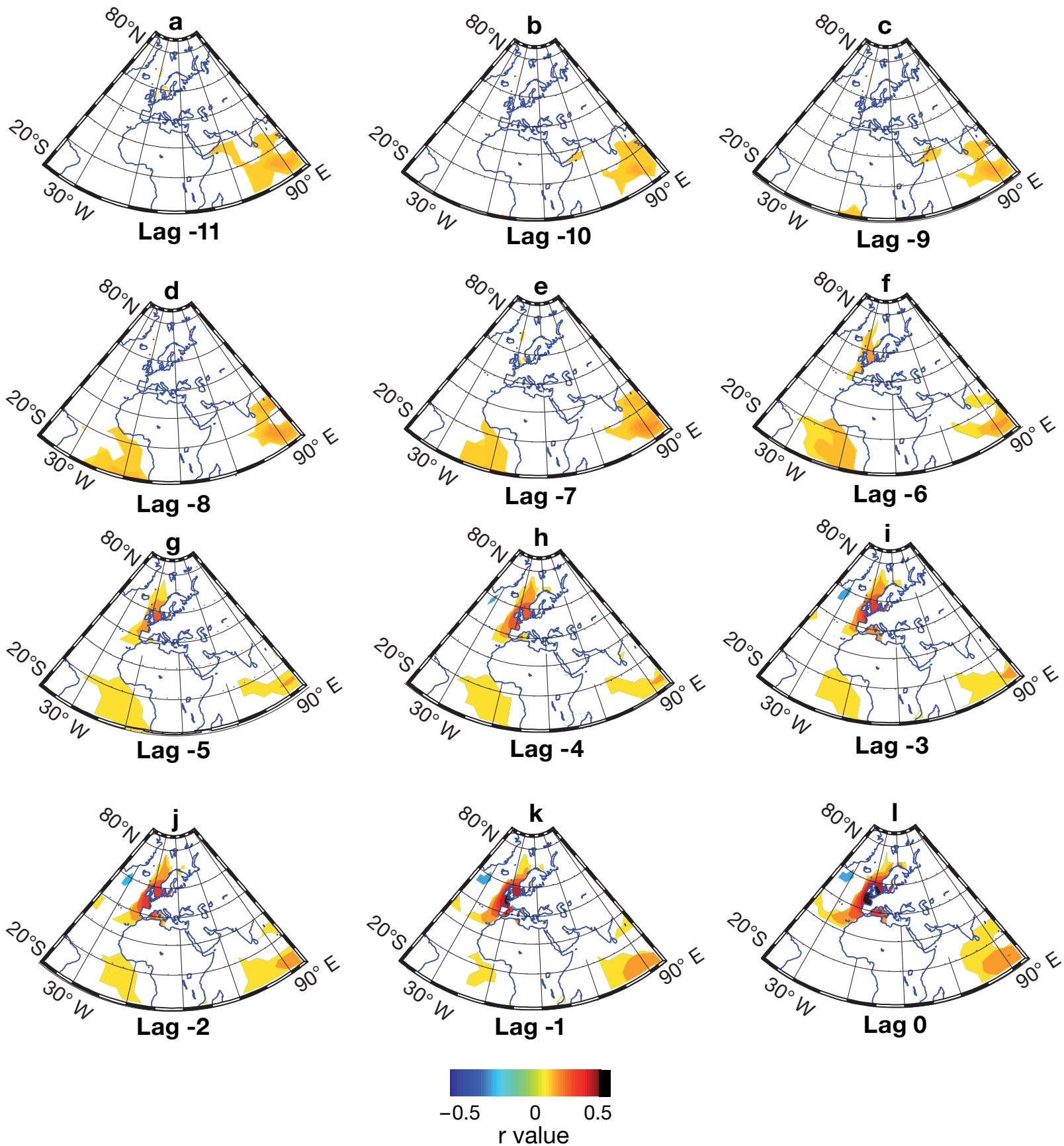

Fig. 7. Evolution of significant lead/lag correlation patterns in months (with $p<1 \%$ from Student's $t$-test) between SST anomalies over the Atlantic and Indian oceans and the GS temperature anomalies for the 1857-2004 period. Lagged correlations from -11 mo to 0 mo are shown from (a) to (1) respectively

plots starting with the 0.2 cycle/yr), thus missing, for example, the significant QB peak period.

The highly significant $3.9 \mathrm{yr}$ peak period (1\% level) for GHD is barely significant for the GS temperature time-series, but is significant at the $5 \%$ level for the winter temperature anomalies in the Parisian region and provides additional evidence for some link between Pinot noir bud breaking and GHD (see also
Jones 2008). The effects of the low-frequency winter climate variability on Pinot noir dormancy (when roots take up nutrients to store energy), on bud breaking, and therefore on GHD, remain to be fully studied. Here results indicate that dormancy and dormancy breaking in Burgundy may be directly affected by the climatic variability of winters around quasi-quadrennial periods. 
Interannual and low-frequency climate variability have been detected by Plaut et al. (1995) when they analyzed only the central England temperature timeseries. Linkages with local air temperature and harvest dates have also been obtained by other teams for Austria and Switzerland (Maurer et al. 2009, Meier et al. 2007). It is clear that socio-economic issues have modulated the climate variability-GHD relationships. It is also worthwhile to note the discrepancies which existed during the 1785-1812 period. The 1783-1785 period coincided with the eruption of the Icelandic volcano Laki, whilst 1790 onward was in phase with the onset of Dalton minimum with weak solar activity. The 'Laki Fog' affected Western Europe, resulting in destructive summer hailstorms and colder winters.

In this paper, detrended and robust anomalous SST spatial patterns (horseshoe/tripole types) associated with GS temperature anomaly time-series, similar to the IA and QB patterns displayed in Figs. $5 \& 6$, are also found in the Atlantic during winter-springsummer (Fig. 7). On these time-scales, when the eastern North Atlantic and the western Mediterranean basin become first warmer/cooler, they led to warmer/ cooler GS temperature. These early patterns contributed to GHD departures. Moreover, it was recognized that the low frequency MD/AMO climate signal was likely to amplify/diminish the intensity of the IA and QB SST anomalous patterns, e.g. during the late 1960s when the AMO changed phases.

\section{CONCLUSIONS}

Both natural IA and QB variability could be modified by anthropogenically induced climate change through changes in the THC and/or frequencies of extreme events, including atmospheric blocking over western Europe and rapid changes in growing degree-days (Fluctuation 11, Fig. 2). The upper-ocean (global and Atlantic) and land warming accelerated 2 decades ago (from possible combination of natural and anthropogenic influences) with positive feedbacks through hydrodynamic and radiative teleconnections (Compo \& Sardeshmukh 2009). From a 'human history of climate approach', climate effects on harvest crises during the pre-industrial era have been highlighted (Le Roy Ladurie 2005). In the Parisian and Burgundy regions, yearly minimum temperature increased by $\sim 1.1$ and $0.9^{\circ} \mathrm{C}$ during the 20th century, respectively. This temperature increase in the Burgundy region is mainly observed at night during the last half of the summer (Moisselin et al. 2002). Advanced knowledge of evolution and phasing of natural climate signals as identified in this study, contribute to decision making in the viticulture and wine industry, as discussed by
Bindi \& Fibbi (2000). It has been proposed for example that in the 'Pacific sector, climate variability might be as important, or more so, to the wine industry, rather than climate change' (Jones \& Goodrich 2008). We envisage that the Pinot noir varietal grape, with its narrow climatic niche (i.e. $\sim 2^{\circ} \mathrm{C}$, Jones 2008 ), will be partly eliminated from the Côte de Beaune region of Burgundy and/or be replaced by other varieties, thus modifying the qualitative hierarchy of vineyards (Kenny \& Harrison 1992) as a result of climate variability and climate change $\left(\sim 0.5^{\circ} \mathrm{C}\right.$ increase during the last $\left.20 \mathrm{yr}\right)$.

Acknowledgements. Y.M.T. thanks Ted Walker for processing the joint SST/SLP EOF analyses. Thanks also to Mike Purdy and Philippe Dandin, Directors of LDEO of Columbia University and Department of Climatology (Météo-France), respectively, for their unconditional support. This is LDEO contribution number 7436 .

\section{LITERATURE CITED}

Basnett TA, Parker DE (1997) Development of the global mean sea level pressure data set GMSLP2. Clim Res Tech Note 79, Hadley Centre, Met Office, Exeter

Bindi M, Fibbi L (2000) Modeling climate change impacts at the site scale on grapevine. In: Downing TE, Harrison PA, Butterfield RE, Lonsdale KG (eds) Climate change, climatic variability and agriculture in Europe: an integrated assessment. Res Rep no. 21, Environ Change Inst, University of Oxford, p 117-134

Bois B (2007) Ce que nous aprennent le climat récent et les observations phénologiques sur les effets du changement climatique en Gironde viticole. 8èmes journees techniques du CIVB, Actes 72-80, March 13, 2007, Bordeaux-Lac

Chabin JP, Madelin M, Bonnefoy C (2007) Les vignobles beaunois face au réchauffement climatique. In: Peyrard J, Fontaine B (eds) Proc Int Coll 'Réchauffement climatique, quels impacts probables sur les vignobles?' Dijon, March 28-30, 2007

Chuine I, Yiou P, Viovy N, Seguin B, Daux V, Leroy Ladurie E (2004) Grape ripening as a past climate indicator. Nature 432:289-290

Compo GP, Sardeshmukh PD (2009) Oceanic influences on recent continental warming. Clim Dyn 32:333-342

Cuccia C (2008) Changements climatiques observés en Bourgogne depuis 1961: Etude des variations de températures et de précipitations. Mémoire de Master, Université de Bourgogne, Dijon

Daux V (2004) Annexe vendémiologique. Dates de vendanges bourguignonnes (XIVème XXIème siècles). In: Le Roy Ladurie E, Vasak A (eds) Abrégé d'histoire du climat: du moyen age à nos jours. Fayard Publisher, Paris, p 163-170

> Delworth TL, Mann ME (2000) Observed and simulated multi-decadal variability in the Northern Hemisphere. Clim Dyn 16:661-676

Encyclopédie (1777) Dictionnaire raisonné des sciences, des arts et des métiers, Vol 4. Diderot D, D'Alembert JB le R (eds) Faculté des Lettres et Université de Lausanne, Pellet, Geneva

- Etien N, Daux V, Masson-Delmotte V, Stievenard M and others (2008) A bi-proxy reconstruction of Fontainebleau (France) growing season temperature from A.D. 1596 to 2000. Clim Past 4:91-106 
García de Cortázar IA (2006) Adaptation du modèle STICS à la vigne-utilisation dans le cadre d'une étude d'impact du changement climatique à l'échelle de la France (Adaptation of the STICS model to vines - use within the framework of a study of the impact of global warming in France). PhD thesis, Ecole Nationale Supérieure Agronomique, Montpellier

Gray ST, Graumlich LJ, Betancourt JL, Pederson GT (2004) A tree-ring based reconstruction of the Atlantic MultiDecadal Oscillation since 1567 A.D. Geophys Res Lett 31:L12205. doi:10.1029/2004GL019932

Hetzinger S, Pfeiffer M, Dullo WC, Keenlyside N, Latif M, Zinke J (2008) Caribbean coral tracks Atlantic multidecadal oscillation and past hurricane activity. Geology 36:11-14

Jones GV (2006) Climate change and wine: observations, impacts and future implications. Aust NZ Wine Industry $\mathrm{J}$ 21:21-26

Jones GV (2008) Climate structure, phenology, and change in Pinot noir wine regions. American Society of Enology and Viticulture (ASEV) Joint Burgundy-California-Oregon Symposium. Southern Oregon University, Portland, OR, June 17-20

> Jones GV, Davis RE (2000) Using a synoptic climatological approach to understand climate/viticulture relationships. Int J Climatol 20:813-837

Jones GV, Goodrich GB (2008) Influence of climate variability on wine regions in the western USA and on wine quality in the Napa Valley. Clim Res 35:241-254

Kenny GJ, Harrison PA (1992) The effects of climate variability and change on grape suitability in Europe. J Wine Res 3:163-183

Kerr RA (2000) A North Atlantic climate pacemaker for the centuries. Science 288:1984-1986

Kushnir Y (1994) Interdecadal variations in North Atlantic sea surface temperature and associated atmospheric conditions. J Clim 7:141-157

Le Roy Ladurie E (2005) Canicule, fraîcheurs, vendanges (Dog-days, cold periods, grape-harvests) (France, XVèmeXIXème siècles). C R Biol 328:213-222

Le Roy Ladurie E, Daux V, Luterbacher J (2006) Le climat de Bourgogne et d'ailleurs au XIV-XX siècles. Hist Econ Soc 3:421-436

Manley G (1974) Central England temperatures: monthly means 1659 to 1973. Q J R Meteorol Soc 100:389-405

- Mann ME, Park J (1999) Oscillatory spatio-temporal signal detection in climate studies: a multiple-taper spectral domain approach. Adv Geophys 41:1-131

Maurer C, Koch E, Hammerl C, Hammerl T, Pokorny E (2009) Klosterneuburg wine and climate change in lower Austria (BACCHUS) temperature reconstruction for the period 16th to 18th centuries from Viennese and Klosterneuburg grape harvest dates. J Geophys Res 114:D22106 doi:

Editorial responsibility: Tim Sparks, Cambridge, UK

\subsection{9/2009JD011730}

Meier N, Ruthishauser T, Pfister C, Wanner H, Luterbacher J (2007) Grape harvest days as proxy for Swiss April to August temperature reconstruction back to A.D. 1480. Geophys Res Lett 34:L20705 doi:10.1029/2007GL031381

Moisselin JM, Schneider M, Canellas C, Mestre O (2002) Les changements climatiques en France au XXème siècle. Meteorologie 8:45-56

> Ottera OE, Bentsen M, Drange H, Suo L (2010) External forcing as a metronome for Atlantic Multidecadal Variability. Nat Geosci 3:688-694

Parker DE, Horton EB (2005) Uncertainties in the central England temperature series since 1878 and some changes to the maximum and minimum series. Int $\mathrm{J}$ Climatol 25: 1173-1188

Plaut G, Ghil M, Vautard R (1995) Interannual and interdecadal variability in 335 years of central England temperatures. Science 268:710-713

Rayner NA, Parker DE, Horton EB, Folland $\mathrm{K}$ and others (2003) Global analyses of SST, sea ice and night marine air temperature since the late nineteenth Century. J Geophys Res 108:4407-4435 doi:10.1029/2002JD002670

Rousseau D (2009) Les températures mensuelles en région parisienne de 1676 à 2008. Meteorologie 8:43-55

Schlesinger ME, Ramankutty N (1994) An oscillation in the global climate system of period $65-70$ years. Nature 367 : 723-726

Sutton RT, Hodson DLR (2005) Atlantic Ocean forcing of north American and European summer climate. Science 309: $115-118$

Tourre YM, Paz S, Cassou C, Kutiel H (2006) Atmospheric dynamics over northwest Africa and linkages with Sahelian rainfall. Geophys Res Lett 33:L14808 doi:10.1029/ 2006GL026695

Tourre YM, Paz S, Kushnir Y, White WB (2010) Lowfrequency climate variability in the Atlantic basin during the 20th century. Atmos Sci Lett 11: 180-185 doi: 10.1002: asl.265

van Engelen AFM, Geurts HAM (1985) Nicolaus Cruquius (1678-1754) and his meteorological observations. In: Historische weerkundige waarnemingen. Vol 4. Publication 165-IV, Royal Netherlands Meteorological Institute (KNMI), de Bilt

Yousef SM (2000) The solar Wolf-Gleissberg cycle and its influence on the earth. Proc Int Conf for Environ Hazard (ICEHM) 2000, Cairo University, p 267-293. Available at: www.virtualacademia.com/pdf/cli267_293.pdf

Zumbühl HJ (1980) Die Schwankungen der Grindelwaldgletscher in den historischen Bild- und Schriftquellen des 12. bis 19. Jahrhunderts. Ein Beitrag zur Gletschergeschichte und Erforschung des Alpenraumes. Denkschriften der Schweizerischen Naturforschenden Gesellschaft (SNG). Birkhäuser, Basel

Submitted: April 21, 2010; Accepted: January 14, 2011

Proofs received from author(s): April 21, 2011 